\title{
DETERMINAÇÃO DA ATIVIDADE ANTAGÔNICA DE BACTÉRIAS LÁCTICAS FRENTE ÀS LINHAGENS DE ESCHERICHIA COLI ISOLADAS DE DEJETOS RESIDÊNCIAIS
}

\author{
Gisele Aparecida Andrade da Sé ${ }^{1}$; Elinalva Maciel Paulo ${ }^{2}$. \\ 1. Bolsista PROBIC, Graduando em Medicina, Universidade Estadual de Feira de Santana, e-mail: \\ giseleandrade_fsa@hotmail.com \\ 2. Orientador, Departamento de Ciências Biológicas, Universidade Estadual de Feira de Santana, e-mail: \\ elinalvamaciel@yahoo.com.br
}

PALAVRAS-CHAVE: bactérias láticas, Escherichia coli, efluentes residenciais.

\section{INTRODUÇÃO}

Os efluentes residenciais albergam uma série de patógenos, sobretudo os provenientes de material fecal; tais efluentes se tornam potencias fontes/veículos de contaminação, possivelmente existindo grande concentração de cepas de E. coli saprófitas e patogênicas. Sendo as últimas causadoras de diarreias. Em relação à etiologia da diarreia; LIMA e DIAS (2010) informam que cerca de 20 a 30\% são de origem bacteriana (Salmonella, Campylobacter jejuni, Yersinia enterocolítica, E. coli enteropatogênica e Clostridium difficile). Destacando entre estas a Escherichia coli, enteropatógeno Gram-negativo da família Enterobacteriaceae. A E. coli apresenta seis patótipos - E. coli enteropatogênica (EPEC), enterohemorrágica (EHEC), enterotoxigênica (ETEC), enteroagregativa (EaggEC), enteroinvasora (EIEC) e de aderência difusa (DAEC). (ALVES, 2009). As EPECs são uma das maiores causas de diarreia em crianças menores de 01 ano.

A terapia oral ou sorológica é fundamental para o controle das gastrenterites, mas também os probióticos são recomendados como tratamento adjuvante, pois reduzem em até $24 \mathrm{hs}$ a duração da diarreia. Tendo seu uso classificação de RECOMENDAÇÃO B; ou seja, com estudos e revisão de caso-controle ou estudo de coorte de boa qualidade. (SOCIEDADE BENEFICENTE ISRAELITA BRASILEIRA, 2013). Probiótico vem do grego e significa "para a vida"; hoje conceituado como micro-organismo vivo, que em quantidades adequadas conferem benefícios à saúde do hospedeiro. (DENIPOTE; TRINDADE e BURINI, 2010). Os gêneros de bactérias mais utilizados como probióticos são Bifidobacterium, Lactobacillus. Os Lactobacillus pertencem ao grupo das bactérias láticas, fazendo parte da microbiota normal do hospedeiro, conferindo diversos benefícios.

Portanto, diante do exposto, este projeto tem como finalidade confrontar in vitro bactérias láticas com sorotipos de E. coli patogênicas isoladas de efluentes residenciais, visando desenvolver em projetos futuros, probióticos para serem administradas em crianças com esta patogenia.

\section{MATERIAL E MÉTODOS}

O trabalho realizado durante os meses de agosto de 2015 até agosto de 2016, em Feira de Santana. A COLETA DE AMOSTRA foi o passo inicial para execução; obtidas de 06 locais na cidade de Feira de Santana.

Tabela 1 - Relação de Locais de Coleta

\begin{tabular}{|l|l|}
\hline Amostra 04 & Bairro CASEB - Anel de Contorno \\
\hline Amostra 05 & Bairro Queimadinha - Avenida José Falcão \\
\hline Amostra 06 & Bairro Rua Nova - Avenida de Canal \\
\hline Amostra 07,08.09 & Bairro Alto do Papagaio \\
\hline
\end{tabular}


Cada uma das amostras foi identificadas e transportadas imediatamente em meio CaryBlair (LEW et al, 1990), sendo refrigeradas para posterior inoculação e conservação.

Para o ISOLAMENTO DE ESCHERICHIA COLI (KONEMAN, 2001) foram utilizados o caldo EC com tubo de Durhan, o Agar Eosina Azul de Metileno (EMB), bem como realização das provas bioquímicas IMViC (INDOLE, METHYL-RED, VOGESPROSKAUER, CitRATE).

As culturas de prova bioquímica positiva, foram encaminhadas para 02 diferentes processos, a PRESERVAÇÃO DAS LINHAGENS (PAULO, 2010) e na ATIVAÇÃO os isolados de E. coli foram inoculados no caldo BHI Processo similar de ativação foi feito com 03 diferentes culturas de Lactobacillus, rotuladas da seguinte forma:

Tabela 2 - Bactérias lácticas testadas para antagonismo

\begin{tabular}{|l|l|}
\hline Lactobacillus paracasei & Disco 01 \\
\hline Lactobacillus plantarum & Disco 02 \\
\hline Lactobacillus acidophilus & Disco 04 \\
\hline
\end{tabular}

Dando seguimento ao trabalho as amostras identificadas positivamente seguiram para TESTE DE ANTAGONISMO. Para avaliar a atividade antagonista das amostras, dois métodos foram utilizados o método de difusão em disco (PAULO, 2001) e a técnica de cultura mista.

\section{RESULTADOS E DISCUSSÃO \\ Inoculação em Caldo EC/ EMB}

As amostras dos 06 diferentes locais foram inoculadas em caldo EC todas as amostras se mostram positivas; com turvação do meio e/ou produção de gás. Posteriormente as amostras foram então inoculadas em meio ágar EMB (Eosin Methylene Blue), um utilizado para isolar e diferenciar bacilos entéricos Gram negativos, por conter corantes eosina e azul-de-metilieno e também agir como inibidor das bactérias Gram-positivas. As colônias de Escherichia coli podem apresentar reflexo verde metálico e bom crescimento com culturas de grande dimensão. Apresentaram verde metálica as amostras 04, 05, 06,08 e 09. A amostra 07 bom crescimento, mas sem a característica do verde metálico.

\section{Provas Bioquímicas}

Prova do Indol

Determinar a capacidade de o organismo degradar triptofano, assim mostraram-se positivas as culturas 04, 05, 06, 07, 08 e 09 .

Prova do Vermelho de metila

Mostraram-se positivas as amostras 05, 07 e 09; já as amostras 04, 06 e 08 foram negativas. Determina-se a capacidade dos microrganismos em oxidar a glicose com produção e manutenção de concentrações altas de produtos finais ácidos.

Prova de Voges-Proskauer

Também efetuda no meio MR - VP (Methyl Red, Voges - Proskauer), determina-se a capacidade do micro-organismo fabricar produtos finais não ácidos ou neutros, como acetilmetilcarbinol. Se formação de cor rosa/vermelha na cultura, 15 minutos após a adição do reagente a prova é positiva. Se não há formação dessa cor a prova é negativa. As culturas negativas foram (04, 05, 06, 07, 08 e 09).

Prova da utilização do citrato

Diferencia microrganismos que usem o citrato como única fonte de carbono. A positividade é demonstrada pela presença de crescimento na superfície inclinada e 
coloração azul. O que não é visto nas culturas negativas. Todas as culturas mostraramse negativas $(04,05,06,07,08$ e 09$)$.

Assim após realização das provas IMViC; as amostras 05, 07 e 09 foram as que apresentaram maior compatibilidade com E. coli.

\section{Teste de Antagonismo}

Utilizado para determinar a sensibilidade bacteriana in vitro frente a agentes antimicrobianos ou de outras substâncias.

No método de difusão em disco (PAULO, 2010); os halos foram medidos em milímetros com paquímetro. $\mathrm{O}$ halo de inibição representa a área sem crescimento detectável a olho nu, estes halos foram comparados com o halo do antibiótico controle. Na AMOSTRA 05, o antibiótico com halo de inibição de $14 \mathrm{~mm}$, não houve formação de halo de inibição em nenhum dos Lactobacillus rotulados como 04 e 01, mas o Lactobacillus rotulado como 02 apresentou discreto halo de inibição de $2 \mathrm{~mm}$. Na AMOSTRA 07, nenhum dos Lactobacillus mostraram halo de inibição. O disco controle halo de $29 \mathrm{~mm}$. E por fim na AMOSTRA 09, também não houve inibição.

Em resumo, no teste de antagonismo em disco apenas no disco 02 (Lactobacillus plantarum) houve formação de halo de inibição de $2 \mathrm{~mm}$, que quando comparado com o antibiótico controle, mostra-se não efetivo.

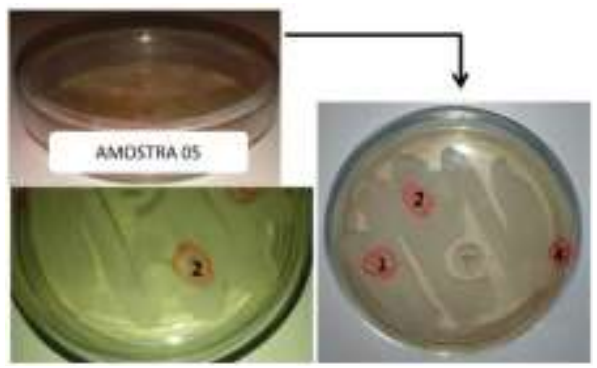

Figura 01 - Teste Antagonismo em Disco - Amostra 05

Já no método de cultura mista, o controle positivo que consistiu no isolado de E. coli (AMOSTRA 07), apresentou crescimento; e o controle negativo que consistiu em isolado de Lactobacillus acidophilus (04) não apresentou crescimento. Ou seja, na inoculação da mistura (E. coli e Lactobacillus) em meio Ágar nutriente só poderia haver crescimento de E. coli.

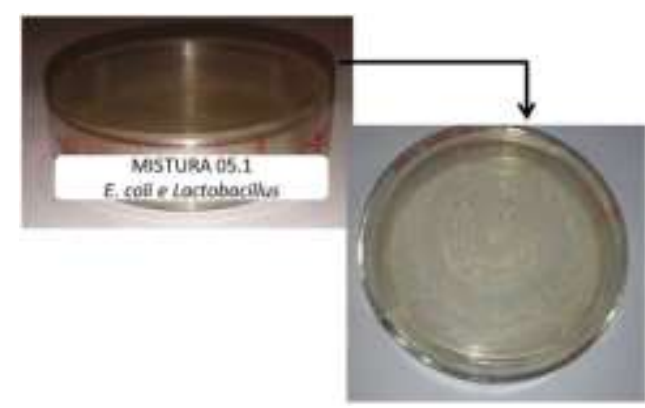

Figura 02 - Teste Antagonismo Mistura Mistura 05.1

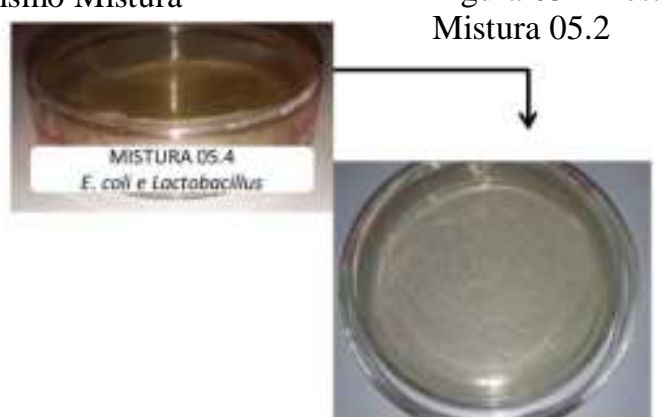

Figura 04 - Teste Antagonismo Mistura Mistura 05.4 
Dessa forma, a AMOSTRA 05 de E.coli mostrou-se sensível às 03 espécies de Lactobacillus, tendo em vista que as inoculações de suas misturas não apresentaram crescimento. Em contra partida as AMOSTRAS 07 e AMOSTRAS 09 não apresentaram sensibilidade, pois as inoculações de suas misturas mostram crescimento. Em resumo, a presença de antagonismo nos diferentes métodos e com as diferentes culturas está expresso na tabela abaixo.

\begin{tabular}{|c|c|c|c|}
\hline & & Antagonismo & \\
\hline & Amostra & Positivo & Negativo \\
\hline \multirow{3}{*}{ 递兽 } & Amostra 05 & + Lactobacillus plantarum & \\
\hline & Amostra 07 & & - \\
\hline & Amostra 09 & & - \\
\hline \multirow{5}{*}{ 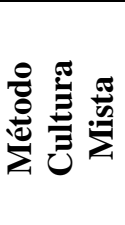 } & Mistura 05.1 & + Lactobacillus paracasei & \\
\hline & Mistura 05.2 & + Lactobacillus plantarum & \\
\hline & Mistura 05.4 & + Lactobacillus acidophilus & \\
\hline & Mistura 07.1/ 07.2/ 07.4 & & - \\
\hline & Mistura 09.1/ 09.2/ 09.4 & & - \\
\hline
\end{tabular}

\section{CONSIDERAÇÕES FINAIS}

Concluindo os Lactobacillus apresentaram antagonismo positivo apenas para AMOSTRA 05 de E. coli, o que pode significar diferentes virulências entre as cepas de E. coli encontradas nas amostras 05, 07 e 09. Assim, mais estudos in vitro necessitam ser realizados para identificação dos possíveis fatores de virulência da $E$. coli, além de teste adicionais de antagonismo dos Lactobacillus contra E.coli e até mesmo avaliação do sinergismo dos Lactobacillus com antibióticos. O que poderia demonstrar a importância do uso de probióticos como terapia adjuvante no tratamento de gastroenterites de etiológica bacteriana por Escherichia coli. Com intuito de não apenas repor a microbiota intestinal, mas também atuar como um antagonista do crescimento da Escherichia coli.

\section{REFERÊNCIAS}

DENIPOTE, F.G.; TRINTADE, E.B.S.N.; BURINI, R.C. Probióticos e prebióticos na atenção primária ao câncer de cólon. Arquivo de Gastroenterologia. São Paulo, vol.47, n.1, pp.93-98, jan-mar 2010.

KONEMAN, E. W., ALLEN, S. D., JANDA, W. M., SCHRECKENBERGER, P. C., WINN, W. C. Diagnóstico Microbiológico. 6 6. Edição. Editora Guanabara Koogan. 2008.

LABORCLIN PRODUTOS PARA LABORATÓRIOS LTDA. Manual para Antibiograma. Acesso: 29 jul de 2016.2 Disponível <http://www.interlabdist.com.br/dados/noticias/pdf_190.pdf>

LIMA, R. M.; DIAS, J. A. Gastroenterite Aguda. Nascer e Crescer Revista do Hospital de Crianças Maria Pia. (?) vol.19, n.2, pp.85-90, 2010.

MURRAY, P. R ROSENTHAL, K. S., PFALLER, M. A. Microbiologia Médica / Patrick R. Murray,; [traduçãoCarlos Pelleschi Taborda... et al.]. - Rio de Janeiro: Elsevier, 2009.

PAULO, E. M. 2010. Produção de exopolissacarídeos (EPS) por bactérias láticas visando microencapsulação de Lactobacillus acidophilus La-5 pelo processo de Spray drying. 2010. Tese 212f. (Doutorado em Biotecnologia), Departamento de Ciências Biológicas, Universidade Estadual de Feira de Santana, Feira de Santana.

SOCIEDADE BENEFICENTE ISRAELITA BRASILEIRA. Diarreia aguda em crianças $e$ adolescentes - Diretrizes para o diagnóstico e tratamento. 2013. 